\title{
Feedback Activation of Basic Fibroblast Growth Factor Signaling via the Wnt/ $\beta$-Catenin Pathway in Skin Fibroblasts
}

\section{OPEN ACCESS}

Edited by:

Ajay Sharma,

Chapman University, USA

Reviewed by:

Martina Schmidt,

University of Groningen, Netherlands

Caroline Gaucher,

University of Lorraine, France

Pavel I. Nedvetsky,

Flanders Institute for Biotechnology,

Belgium

*Correspondence:

Litai Jin

jin_litai@126.com

Xiaokun Li

proflxk@163.com

Yuanhu Xuan

yhxuan@wzmc.edu.cn

tThese authors have contributed equally to this work.

Specialty section:

This article was submitted to Experimental Pharmacology and Drug

Discovery,

a section of the journal

Frontiers in Pharmacology

Received: 30 September 2016

Accepted: 17 January 2017

Published: 03 February 2017

Citation:

Wang $X$, Zhu Y, Sun C, Wang T,

Shen Y, Cai W, Sun J, Chi L, Wang $H$, Song N, Niu C, Shen J, Cong W, Zhu Z, Xuan Y, Li X and Jin L (2017) Feedback Activation of Basic Fibroblast Growth Factor Signaling via the $W n t / \beta$-Catenin

Pathway in Skin Fibroblasts.

Front. Pharmacol. 8:32.

doi: 10.3389/fphar.2017.00032

\begin{abstract}
Xu Wang ${ }^{1 t}$, Yuting Zhu ${ }^{21}$, Congcong Sun ${ }^{1 \dagger}$, Tao Wang ${ }^{1}$, Yingjie Shen ${ }^{1}$, Wanhui Cai ${ }^{1}$, Jia Sun ${ }^{1}$, Lisha Chi ${ }^{1}$, Haijun Wang ${ }^{3}$, Na Song ${ }^{3}$, Chao Niu' ${ }^{1}$, Jiayi Shen ${ }^{1}$, Weitao Cong ${ }^{1}$, Zhongxin Zhu' ${ }^{1}$, Yuanhu Xuan ${ }^{1 *}$, Xiaokun $\mathrm{Li}^{1 *}$ and Litai Jin ${ }^{1 *}$

1 Key Laboratory of Biotechnology Pharmaceutical Engineering, School of Pharmaceutical Sciences, Wenzhou Medical University, Wenzhou, China, ${ }^{2}$ Haining Hospital of Traditional Chinese Medicine, Haining, China, ${ }^{3}$ School of Basic Medical Sciences, Xinxiang Medical University, Xinxiang, China
\end{abstract}

Skin wound healing is a complex process requiring the coordinated behavior of many cell types, especially in the proliferation and migration of fibroblasts. Basic fibroblast growth factor (bFGF) is a member of the FGF family that promotes fibroblast migration, but the underlying molecular mechanism remains elusive. The present RNA sequencing study showed that the expression levels of several canonical Wnt pathway genes, including Wnt2b, Wnt3, Wnt11, T-cell factor 7 (TCF7), and Frizzled 8 (FZD8) were modified by bFGF stimulation in fibroblasts. Enzyme-linked immunosorbent assay (ELISA) analysis also showed that Wnt pathway was activated under bFGF treatment. Furthermore, treatment of fibroblasts with lithium chloride or IWR-1, an inducer and inhibitor of the Wht signaling pathway, respectively, promoted and inhibited cell migration. Also, levels of cytosolic glycogen synthase kinase 3 beta phosphorylated at serine ${ }^{9}$ (pGSK3 $\beta$ $\operatorname{Ser}^{9}$ ) and nuclear $\beta$-catenin were increased upon exposure to bFGF. Molecular and biochemical assays indicated that phosphoinositide 3-kinase (PI3K) signaling activated the GSK3 $\beta / \beta$-catenin/Wnt signaling pathway via activation of c-Jun $\mathrm{N}$-terminal kinase (JNK), suggesting that PI3K and JNK act at the upstream of $\beta$-catenin. In contrast, knock-down of $\beta$-catenin delayed fibroblast cell migration even under bFGF stimulation. RNA sequencing analysis of $\beta$-catenin knock-down fibroblasts demonstrated that $\beta$-catenin positively regulated the transcription of bFGF and FGF21. Moreover, FGF21 treatment activated $\mathrm{AKT}$ and $\mathrm{JNK}$, and accelerated fibroblast migration to a similar extent as bFGF does. In addition, ELISA analysis demonstrated that both of bFGF and FGF21 were auto secretion factor and be regulated by Wnt pathway stimulators. Taken together, our analyses define a feedback regulatory loop between bFGF (FGF21) and Wnt signaling acting through $\beta$-catenin in skin fibroblasts.

Keywords: cell migration, bFGF, transcriptome, Wnt signaling pathway, $\beta$-catenin, GSK3 $\beta$

Abbreviations: bFGF, basic fibroblast growth factor; ChIP, chromatin immunoprecipitation; DMSO, dimethyl sulfoxide; ECM, extracellular matrix; ELISA, enzyme-linked immunosorbent assay; FBS, fetal bovine serum; FGFR, fibroblast growth factor receptor; FZD8, Frizzled 8; GAPDH, glyceraldehyde-3-phosphate dehydrogenase; GO, gene ontology; GSK-3 $\beta$, glycogen synthase kinase 3 $\beta$; JNK, c-Jun N-terminal kinase; LiCl, lithium chloride; PBS, phosphate buffered saline; PI3K, phosphatidylinositol 3-kinase; qRT-PCR, quantitative real-time polymerase chain reaction; RNA-Seq, RNA-sequencing; siRNA, small interfering RNA; TCF7, T-cell factor 7. 


\section{INTRODUCTION}

Skin serves as a barrier to protect internal tissues from the external environment, playing a crucial role in life sustenance (Enoch and Price, 2004). Skin wounding can be caused by tears, cuts, or contusions (Pazyar et al., 2014), and presents as a split in the epidermis, as well as deeper punctures extending to the dermis, subcutaneous fat, fascia, muscles, or the bone itself (Enoch and Price, 2004). The net result is morbidity from loss of function, negative psychosocial effects from disfigurement, or even mortality from loss of the skin's barrier function (Amini-Nik et al., 2014). Therefore, it is essential that any wound sustained by the skin is fully healed to restore homeostasis.

Wound healing is a complex biological process (Thamm et al., 2013) that requires the actions of various cell types, including keratinocytes, fibroblasts, endothelial cells, macrophages, and platelets. These cells undergo proliferation, migration, infiltration, and inflammatory events, in addition to stimulation by and activation of growth factors and ECM signaling molecules to rebuild the skin (Martin, 1997; Wagner and Wehrmann, 2007). Cell migration and proliferation are important processes that both require and trigger new ECM synthesis, thereby contributing to wound healing (Epstein et al., 1999). Fibroblast proliferation and migration are especially critical to the formation of granulation tissue and wound healing (Kanazawa et al., 2010).

Wound healing processes are regulated by numerous growth factors, including FGFs (Xuan et al., 2014). As one of the FGFs, bFGF/FGF2 is involved in many biological activities (e.g., cell growth, cell and tissue differentiation, and cell migration) (Dvorak and Hampl, 2005). Our previous studies reported that bFGF promoted wound closure through the PI3K/Rac1/JNK pathway and NFKB-JNK pathway (Xuan et al., 2014, 2016).

The canonical Wnt signaling pathway, also known as the $\beta$-catenin pathway or the $\beta$-catenin/ TCF pathway (Shtutman et al., 1999), likewise regulates a wide array of biological processes (Moon et al., 2004; Clevers, 2006; Brack et al., 2007). The hallmark of the $\mathrm{Wnt} / \beta$-catenin pathway is the stabilization of cytosolic $\beta$-catenin. Under unstimulated conditions, $\beta$-catenin is constantly phosphorylated by a destruction complex consisting of GSK3 $\beta$ and other proteins (Gordon and Nusse, 2006); phosphorylated $\beta$-catenin is ubiquitinated by this complex and targeted for degradation by the proteasome (Aberle et al., 1997; Gordon and Nusse, 2006). Activation of the Wnt cascade inhibits GSK3 $\beta$ activity, allowing $\beta$-catenin to accumulate and enter the nucleus, where it associates with TCF/LEF, leading to the transcription of Wnt signaling genes that participate in cell survival, proliferation, and differentiation (Gordon and Nusse, 2006).

Previous study reported that FGF and $\mathrm{Wnt} / \beta$-catenin signaling involved in collective cell migration (Aman and Piotrowski, 2008), additionally, Bergmann et al. (2011) also define the activation of Wnt pathway in fibroblast facilitate the release of collagen. Moreover, stimulation of osteoblast differentiation and bone formation is partially mediated by bFGF modulation of the Wnt pathway (Fei et al., 2011). However, the molecular basis for the relationship between bFGF and Wnt signaling during fibroblast migration is remained to be established.

Here, we performed an RNA sequencing analysis to gain insights into the molecular mechanism of bFGF-mediated wound healing, and identified 830 differentially expressed genes in bFGF-treated versus untreated fibroblasts. GO and pathway analyses distinguished a number of significantly altered molecular pathways, especially in the canonical Wnt signaling pathway. Moreover, GSK3 $\beta$ activity was decreased in response to bFGF treatment, while knock-down of $\beta$-catenin resulted in delay of cell migration. Lastly, suppression of $\beta$-catenin in fibroblasts led to repression of $b F G F$ and FGF21, which detected with the identical effect on the activation of AKT and JNK, and the acceleration of cell migration.

To date, several studies have drawn attention to the role of FGF21 in modulation glucose homeostasis by binding to FGF receptor $1 \mathrm{c}$ isoform in the present of the cofactor $\beta$-klotho. Here, we report for the first time the involvement of FGF21 in fibroblast migration.

Taken together, our findings provide a new mechanism whereby bFGF (FGF21) and Wnt signaling are tightly connected to maintain fibroblast cell migration through $\beta$-catenin.

\section{MATERIALS AND METHODS}

\section{Ethics Statement}

Human foreskin samples were collected from volunteers at the First Affiliated Hospital, Wenzhou Medical University. All volunteers were informed of the purpose and procedures of this study and agreed to offer their tissue specimens with written consent. All protocols for human studies were approved by the Ethics Committee of the First Affiliated Hospital of Wenzhou Medical University.

\section{Cell Culture}

The NIH/3T3 mouse embryo fibroblast cell lines were purchased from American Type Cell Collection (ATCC, Manassas, VA, USA) and cultured in DMEM, which contained $5.5 \mathrm{mM}$ glucose, $10 \%$ FBS and 1\% penicillin-streptomycin. Cells passaged 3-15 times were selected for the following experiments.

While for primary human foreskin fibroblasts, fat was removed from all tissue samples, which were cut into $3 \mathrm{~mm}$ strips and incubated with $0.05 \%$ dispase neutral protease (SigmaAldrich, St. Louis, MO, USA). The tissues in digestion buffer were incubated with Dulbecco's Modified Eagle's Medium (DMEM; Gibco BRL, Grand Island, NY, USA) supplemented with 10\% FBS (Gibco BRL) and 1\% penicillin-streptomycin (Gibco BRL) at $4^{\circ} \mathrm{C}$ overnight. The epidermis was removed from the dermis, and the dermis was finely minced and placed into FBS-coated $25 \mathrm{~cm}^{2}$ flasks. The flasks were placed horizontally for $1 \mathrm{~h}$ and then vertically for $3 \mathrm{~h}$ in an atmosphere of $5 \% \mathrm{CO}_{2}$ at $37^{\circ} \mathrm{C}$. The tissues were then cultured in DMEM supplemented with $5.5 \mathrm{mM}$ glucose, $10 \% \mathrm{FBS}$, and $1 \%$ penicillin-streptomycin, with subsequent changes of the medium every 3 days. Cultured cells were passaged using $0.25 \%$ trypsin (Gibco BRL) after cell 
confluence reached $\sim 80 \%$. The human fibroblasts were used for various studies described below after 3-6 passages.

\section{Total RNA Extraction, cDNA Synthesis, and Quantitative Real-Time Polymerase Chain Reaction (qRT-PCR)}

Total RNA was extracted from primary human fibroblasts cells with or without $1 \mathrm{~h}$ bFGF treatment $(100 \mathrm{ng} / \mathrm{mL}$ ) (Xuan et al., 2016). Our results showed that bFGF represses the protein levels of $\beta$-catenin in fibroblasts after $30 \mathrm{~min}$ of bFGF treatment (Supplementary Figure S1C). Therefore, total RNA was extracted from the mouse NIH3T3 fibroblast cell line with or without $30 \mathrm{~min}$ bFGF treatment $(100 \mathrm{ng} / \mathrm{mL})$, and $\beta$-catenin knock-down NIH3T3 cells for the RNA-Seq experiments. Cell monolayers were rinsed once with ice-cold phosphate-buffered saline, lysed directly in $3.5 \mathrm{~cm}$ culture dishes by adding $1 \mathrm{~mL}$ of Trizol Reagent (Invitrogen, Carlsbad, CA, USA) to each dish, and scraped with a cell scraper. Chloroform $(0.2 \mathrm{~mL})$ was added to $1 \mathrm{~mL}$ of cell lysate, and total RNA was extracted. Total RNA $(2 \mu \mathrm{g})$ was reverse-transcribed using a GoScript Reverse Transcription Kit (Promega, Madison, WI, USA) according to the manufacturer's instructions. Next, qRT-PCR was performed to quantify the expression of selected genes, as previously described (Zittermann and Issekutz, 2006). The mRNA levels were normalized against that of GAPDH. Gene-specific primer sequences used for qRTPCR are listed in Supplementary Table S1.

\section{RNA Sequencing}

Total RNA extracted from untreated or bFGF-treated (100 ng/mL, $1 \mathrm{~h}$ ) human foreskin fibroblasts and $\beta$-catenin knock-down NIH3T3 cells were used for the RNA sequencing experiments. RNA sequencing was performed using a kit provided by LC Biotech, Co., Ltd (http://www.lc-bio.com/; Hangzhou, China), and data analyses were performed by Novel Bioinformatics, Co., Ltd (http://www.novelbio.com/; Shanghai, China).

\section{Analysis of GO Categories, Signaling Pathways, and Co-expression Networks}

Differentially expressed genes were determined from statistical outcomes by testing for association with biological process GO terms (Consortium, 2006). Fisher's exact test was used to classify the GO categories, and the false discovery rate (FDR) was calculated to correct the $P$-value, where the smaller the FDR, the smaller the error in judging the $P$-value (Dupuy et al., 2007). Enrichment of GO members among differentially expressed probe sets was identified using the one-tailed Fisher's exact test according to $2 \times 2$ contingency tables (Dunnick et al., 2012). This provides a measure of the significance of the function. As the enrichment increases, the corresponding function is more specific, which helps in distinguishing GOs with a more concrete function.

Pathway analysis was used to determine the significance of assorted gene sets according to the Kyoto Encyclopedia of Genes and Genomes (KEGG), Biocarta, and Reactome databases. Fisher's exact test was followed by Benjamini-Hochberg $(\mathrm{BH})$ multiple testing correction to select the most significant pathway(s), and the threshold of significance was defined by the $P$-value and the FDR (Draghici et al., 2007).

\section{Wound Healing Assay}

Cell migration was determined using a standard wound healing scratch assay. Cells were seeded into six-well plates and cultured overnight. Confluent cells were cultured in DMEM supplemented with $0.5 \%$ FBS for $24 \mathrm{~h}$, and then wounded by creating a $1 \mathrm{~mm}$ linear scratch with a sterile pipette tip. Images of the wounded cell monolayers were taken under a Model IX70 Microscope (Olympus, Tokyo, Japan) at 0,12 , and $24 \mathrm{~h}$ after wounding. Cell migration into the wounded area was recorded for $24 \mathrm{~h}$ using the same microscope equipped with a CoolSNAP HQ CCD Camera (Nippon Roper, Chiba, Japan) and MetaMorph Software (Universal Imaging, Co., Ltd, Buckinghamshire, UK). All experiments were performed in the presence of $5 \mathrm{mg} / \mathrm{mL}$ mitomycin-C to inhibit cell proliferation. Concentrations of $\mathrm{LiCl}$ (Sigma) and IM-12 (Selleck), inhibitor of GSK3 $\beta$ and promotor of Wnt signaling, and IWR-1 (Sigma) and XAV-939 (Selleck), inhibitors of Wnt signaling, were tested and shown in Supplementary Figure S1. Concentrations of FGF21 and BGJ 398, an inhibitor of FGFR, were tested and shown in Supplementary Figure S7.

To observe the relationship between Wnt signaling and bFGF activation in cell migration, cells were pretreated with $1.0 \mu \mathrm{M}$ IWR-1, $1.0 \mu \mathrm{M}$ bFGF, or $1.0 \mu \mathrm{M}$ IWR-1 plus $1.0 \mu \mathrm{M}$ bFGF for $1 \mathrm{~h}$ before wounding. $24 \mathrm{~h}$ after wounding, the distance from 20 selected cells and the wound leading edge just after wounding was measured using Image J software (National Institutes of Health).

\section{Western Blot Analysis}

Cells were harvested in an ice-cold lysis solution (7 M urea, $2 \mathrm{M}$ thiourea, 2\% CHAPS, $40 \mathrm{mM}$ Tris base, $40 \mathrm{mM}$ dithiothreitol, and $1 \%$ protease inhibitor) to procure whole cell extracts. KeyGen Nuclear-Cytosol Protein Extraction and KeyGen Mitochondria-Cytosol Protein Extraction Kits (Nanjing KeyGen Biotech., Co., Ltd, Nanjing, China) were used for protein isolation from the nucleus and the cytosol, respectively (Zhang et al., 2010). Protein concentrations were measured using the bicinchoninic acid protein assay reagent (Pierce/Life Technologies, Grand Island, NY, USA). Equal amounts of protein were loaded into each lane of a sodium dodecyl sulfate (SDS)polyacrylamide gel, electrophoretically separated, and transferred onto a polyvinylidene difluoride (PVDF) membrane (Bio-Rad, Hercules, CA, USA). Membranes were blocked with 5\% bovine serum albumin in Tris-buffered saline/Tween 20 (TBST) for $1 \mathrm{~h}$ and then incubated with the following primary antibodies overnight at $4^{\circ} \mathrm{C}$ : anti-GAPDH (Abcam, Cambridge, MA, USA), anti- $\beta$-actin (Cell Signaling Technology, Beverly, MA, USA), anti- $\beta$-catenin (Abcam), anti-phospho-GSK3 $\beta$ (pGSK3 $\beta$ Ser $^{9}$ ) (Cell Signaling Technology), anti-GSK3 $\beta$ (Cell Signaling Technology), anti-pAKT Ser ${ }^{473}$ (Cell Signaling Technology), anti-total-AKT (Cell Signaling Technology), and anti-phosphostress activated protein kinase (pSAPK)/JNK Thr ${ }^{183} / \mathrm{Tyr}^{185}$ (Cell Signaling Technology). After washing three times with TBST, blots were incubated with appropriate secondary antibodies 
(Cell Signaling Technology) at room temperature for $90 \mathrm{~min}$. Finally, after washing with TBST, the antigen-antibody complexes on the PVDF membranes were visualized using an enhanced chemiluminescence kit (GE Healthcare, Piscataway, NJ, USA). Protein levels were normalized against GAPDH using Image J software, as previously described (Fei et al., 2011).

\section{Small Interfering RNA (siRNA) Experiments}

The siRNA targeting the mouse PI3-kinase p110 $\alpha$ (Cat. no. sc-39128) was purchased from Santa Cruz Biotechnology, Inc. (Santa Cruz, CA, USA). NIH3T3 cells were seeded $12 \mathrm{~h}$ before transfection, with a cell density of $30-50 \%$ confluence at the time of transfection. Next, the siRNA (40 nM) was transfected into the cells using Lipofectamine 2000 (Invitrogen) and OptiMEMI reduced serum medium (Gibco BRL). After $24 \mathrm{~h}$ of transfection, cells were processed by semi-quantitative RT-PCR for the detection of PI3K $p 110 \alpha$ mRNA levels and Western blotting for the detection of p-GSK3 $\beta$ Ser$^{9}$ levels.

\section{Silencing of Endogenous $\beta$-Catenin in Fibroblast Cells}

The siRNA sequence used for the knock-down of $\beta$-catenin was as follows: 5' -GAACGCAGCAGCAGTTTGT-3', as described by Singh et al. (2009), (nucleotides 124-142 on NM-007614.3). For lentiviral infection of NIH3T3 cells, cells were seeded at a density of $2 \times 10^{5}$ cells per well in 24-well plates. After overnight culture, various amounts of lentivirus $(3,10$, or $12 \mu \mathrm{L})$ (OBIO Technology, Co., Ltd, Shanghai, China) were added to the wells in the presence of $4 \mathrm{mg} / \mathrm{mL}$ Polybrene (SigmaAldrich, St. Louis, MO, USA). The plates were then centrifuged at 2,500 rpm at room temperature for $1 \mathrm{~h}$ and returned to the culture incubator. $24 \mathrm{~h}$ after infection, the resulting NIH3T3 cell cultures were analyzed for green fluorescence protein expression (GFP; a reporter) by confocal microscopy. Cells treated with $12 \mu \mathrm{L}$ lentivirus were chosen for the knock-down experiments described below.

\section{Enzyme-Linked Immunosorbent Assay}

Enzyme-linked immunosorbent assay was performed to detect the levels of FGFs (bFGF and FGF21, Multi Sciences, China) and Wnt3a (Enzyme-linked Biotechnology, Co., Ltd, Shanghai, China) according to the manufacturer's instructions. Fibroblasts were seeded in 6-well plates and cultured for $24 \mathrm{~h}$. To determine the assay of FGFs secreted by fibroblast, cell culture supernatants were collected after 24,36 , and 48 h, respectively. To determine the effect of $\beta$-catenin on FGFs secretion, after $24 \mathrm{~h}$ incubation, the media were replaced with fresh media containing $1.0 \mu \mathrm{M} \mathrm{LiCl}, 1.0 \mu \mathrm{M}$ IWR-1, $0.5 \mu \mathrm{M}$ IM-12 or $0.5 \mu \mathrm{M}$ XAV-939, and the cells were then cultured for $48 \mathrm{~h}$. To investigate Wnt3a secretion under FGFs treatment, fibroblasts were cultured in the fresh media containing $100 \mathrm{ng} / \mathrm{mL}$ bFGF or FGF21. Then, cell culture supernatants were collected to determine FGFs (bFGF and FGF21) and Wnt3a protein levels.

\section{ChIP Assay}

Chromatin immunoprecipitation assay was performed by using a ChIP assay kit (cat no. 17-295, Millipore, Billerica, MA, USA) according to the manufacturer's instructions. Cells were cross-linked with $1 \%$ formalin. DNA is extracted from immunoprecipitates of $\beta$-catenin Ab (Abcam, ab32572). For PCR, $2 \mathrm{uL}$ from $30 \mathrm{uL}$ of DNA extraction was used. The primer sequences for qRT-PCR are listed in Supplementary Table S1.

\section{Statistical Analysis}

Statistical analysis was performed with GraphPad Prism 5 Software (GraphPad, San Diego, CA, USA). All data were expressed as mean \pm the standard error (SE). Comparisons between two groups were performed using Student's $t$-test.

\section{RESULTS}

\section{Identification of a bFGF-Regulated Transcriptome in Fibroblasts}

To determine the effects of Wnt pathway gene expression after bFGF treatment, gene expression levels were analyzed using primary human fibroblast cells with or without bFGF treatment for $1 \mathrm{~h}$ (Xuan et al., 2016). RNA sequencing results revealed that 830 genes were differentially expressed in bFGF-treated fibroblasts. Among them, 473 genes were down-regulated, while 357 genes were up-regulated $(P<0.05$ and fold change $>1.5)$ (Figure 1A) (Fei et al., 2011).

The significance of these altered gene expression levels was further assessed from statistical outcomes by testing for association with biological process GO terms. Pathway analysis was used to assess the significance of the differentially expressed gene sets according to KEGG, which demonstrated the following gene clusters that were significantly altered in bFGF-treated fibroblasts: seven up-regulated clusters (cytokine-cytokine receptor interactions, ECM-receptor interactions, transcriptional misregulation in cancer, human T-cell lymphotropic virus type 1 (HTLV-1) infection, Salmonella infection, hepatitis $\mathrm{B}$, and hematopoietic cell lineage) and nine down-regulated clusters (Wnt signaling pathway, nuclear factor-kappa B signaling pathway, tumor necrosis factor signaling pathway, ECM-receptor interactions, Hippo signaling pathway, HTLV-1 infection, NOD-like receptor signaling pathway, Hedgehog signaling pathway, and insulin signaling pathway). As shown in Figure 1B, Wnt $2 B$, Wnt11, and $W n t 3$ were down-regulated, whereas Frizzled 8 (FZD8) and T-cell factor 7 (TCF7) were upregulated in bFGF-treated fibroblasts. Furthermore, the changes in Wnt pathway genes (FZD8, Wnt2B, Wnt11, Wnt3, and TCF7) were verified by qRT-PCR, and the data were consistent with the RNA sequencing results (Figure 1C). These findings indicate that bFGF regulates Wnt signaling genes in fibroblasts.

\section{The Wnt/ $\beta$-Catenin Pathway Positively Regulates Fibroblast Migration}

Since the expression levels of key Wnt signaling genes were significantly changed after bFGF treatment in skin fibroblasts, 

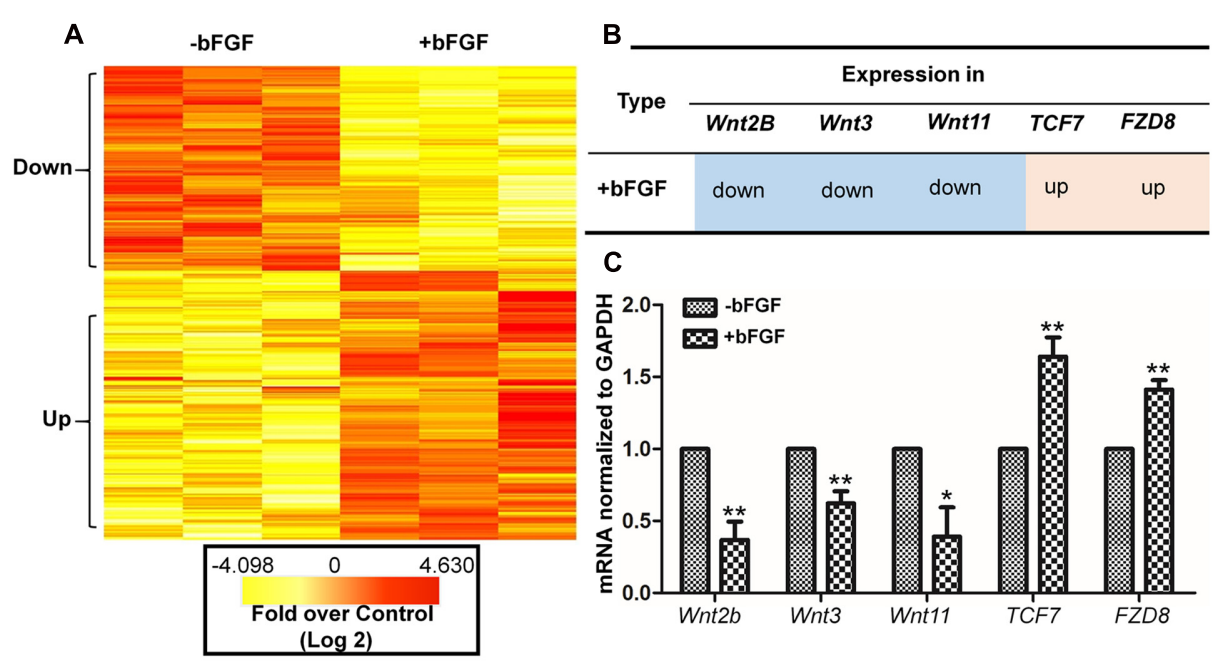

FIGURE 1 | Basic fibroblast growth factor-regulated Wnt signaling genes in skin fibroblasts. (A) Heat map representation of genes whose expression levels were altered after $1 \mathrm{~h}$ of bFGF (100 ng/mL) treatment in human fibroblasts. Gene expression is shown by a pseudocolor scale, with yellow denoting low levels of gene expression, and red denoting high levels of gene expression $(P<0.05)$. (B) bFGF-regulated Wnt-related genes were classified into up-regulated and down-regulated clusters. (C) qRT-PCR was performed to monitor the mRNA levels of FZD8, Wnt2b, Wnt11, Wnt3, and TCF7. GAPDH was used as an internal control. Data represent mean values \pm the SE $\left(n=5\right.$ replicates; ${ }^{*} P<0.05,{ }^{* *} P<0.01$ versus the untreated control group; Student's $t$-test).

the role of Wnt signaling during human fibroblast migration was further analyzed. LiCl is an inhibitor of GSK3 $\beta$ (Klein and Melton, 1996) that activates the Wnt pathway, and accelerated cell migration herein throughout the course of the $24 \mathrm{~h}$ wound healing assay (Figures 2A,B; Supplementary Figure S1). By contrast, the Wnt pathway inhibitor, IWR-1 (Clevers and Nusse, 2012), delayed cell migration. Interestingly, bFGF accelerated migration of the fibroblasts, and slightly overturned the reduced cell migration caused by IWR-1 (Figures 2A,B). In addition, this critical effect of Wnt pathway on wound healing was further confirmed by IM-12 and XAV-939, another common used agonist and antagonist of Wnt signaling, respectively (Supplementary Figure S1) (Jeong et al., 2014; Cai et al., 2016).

\section{Effect of bFGF on Nuclear $\beta$-Catenin Accumulation and GSK3 $\beta$ Phosphorylation}

The results from the cell migration assay indicated that Wnt signaling is important for skin wound healing. $\beta$-catenin is known as an essential transcription factor in the Wnt pathway that translocates from the cytosol to the nucleus to activate downstream target genes (Salic et al., 2000). Western blot analysis showed that bFGF or $\mathrm{LiCl}$ treatment increased nuclear $\beta$-catenin level, whereas IWR-1 reduced nuclear $\beta$-catenin level (Figures 2C,E).

To further analyze the potential mechanism by which bFGF regulates $\beta$-catenin degradation by proteasome, GSK3 $\beta$ phosphorylation levels were analyzed, because GSK3 $\beta$ phosphorylates $\beta$-catenin which further results in its degradation. On the other hand, GSK3 $\beta$ phosphorylation is reportedly involved in cell migration in various cellular systems (Etienne-Manneville and Hall, 2003; Bianchi et al., 2005; Sun et al., 2009; Harris and Nelson, 2010). Phosphorylation at Ser-9 inactivates GSK3 $\beta$, which results in $\beta$-catenin stabilization and nuclear accumulation and leads to enhanced Wnt signaling (Fei et al., 2011). Therefore, we tested the effect of bFGF on GSK3 $\beta$ phosphorylation level. Figures 2D,F showed that bFGF and $\mathrm{LiCl}$ treatment increased the phosphorylation of GSK3 $\beta$ at $\operatorname{Ser}^{9}$ in fibroblasts, but no significant differences were observed between IWR-1-treated and control groups (Boku et al., 2013). These results suggested that bFGF inhibits GSK3 $\beta$ activity through increased phosphorylation of $\mathrm{Ser}^{9}$.

\section{bFGF/PI3K/JNK Signaling Activates the Wnt/ $\beta$-Catenin Signaling Pathway}

The PI3K/Rac1/JNK pathway functions at the downstream of bFGF during fibroblast migration (Kanazawa et al., 2010). Moreover, PI3K induces phosphorylation of AKT at Ser ${ }^{473}$, thereby facilitating the phosphorylation of GSK3 $\beta$ at $\operatorname{Ser}^{9}$, which in turn inactivates GSK3 $\beta$ kinase activity (Cohen and Frame, 2001; Engelman et al., 2006). To verify the relationship between PI3K-AKT and GSK3 $\beta$ in fibroblast, biochemical and pharmacological tests were further performed. Application of the PI3K inhibitor, LY294002 (cell signaling technology), substantially suppressed AKT and GSK3 $\beta$ phosphorylation levels in fibroblasts (Figures 3A-C). Contrarily, $\mathrm{LiCl}$ treatment did not change pAKT levels (Figure 3D), while pGSK3 $\beta$ Ser$^{9}$ levels were increased (Figure 3E). In view of the fact that bFGF induced the neuroblast migration is mediated by modulating FGFR1 signaling via the PI3K P110 alpha isoform, specifically through the phosphorylation of PI3K downstream effectors, AKT and GSK3 $\beta$ (Hu et al., 2013), PI3K P110 alpha siRNA was transformed into NIH3T3 cells and PI3K levels were monitored. The data showed that both siRNA-mediated suppression of PI3K 


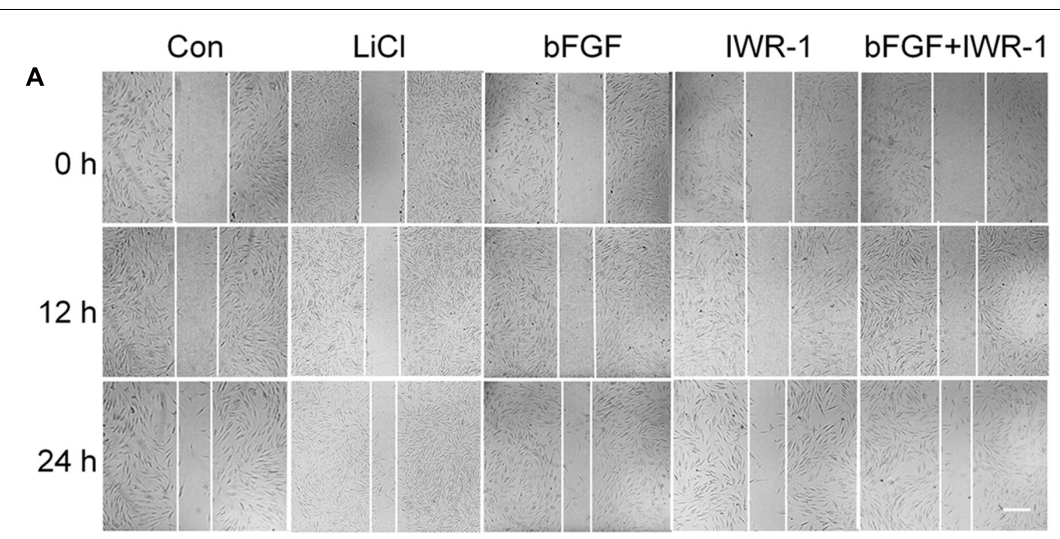

B

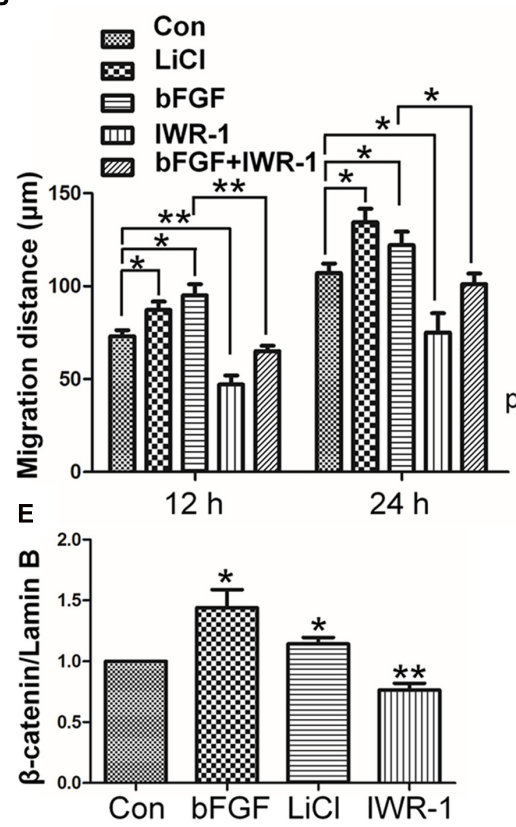

c

Nucleus

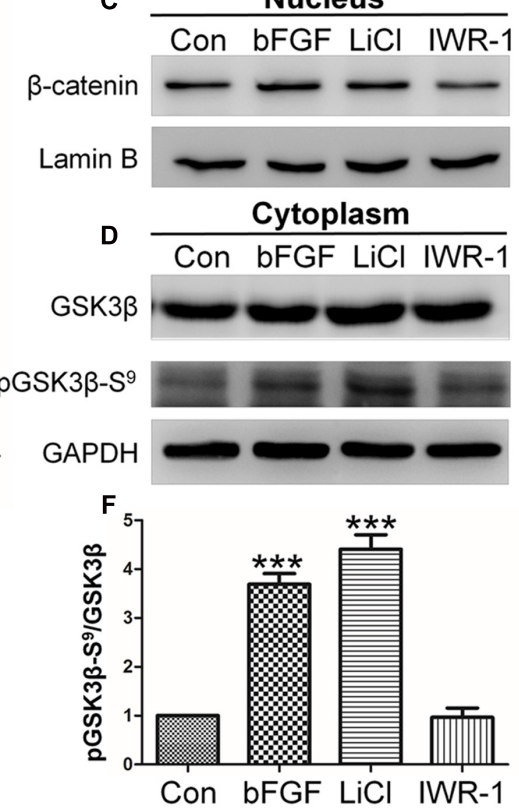

FIGURE 2 | Effects of LiCl, bFGF, and IWR-1 treatment on cell migration, nuclear $\beta$-catenin, and GSK3 $\beta$ phosphorylation levels in skin fibroblasts. (A) A wound healing assay was performed after treatment with LiCl (1.0 $\mu \mathrm{M})$, bFGF (100 ng/mL), IWR-1 (1.0 $\mu \mathrm{M})$, or bFGF (100 ng/mL) plus IWR-1 (1.0 $\mu \mathrm{M})$. The wounded cell monolayers were photographed at $\mathbf{0}, 12$, and $24 \mathrm{~h}$ after treatment. White vertical lines indicate the borders of the wound area. Bar $=500 \mu \mathrm{m}$. (B) Cell migration distances shown in (A) were measured and plotted $(* P<0.05, * * P<0.01$; Student's $t$-test). (C) Nuclear $\beta$-catenin levels were altered upon treatment with bFGF, LiCl, or IWR-1. Preparation of nuclear lysates and Western blots were performed at 30 min (bFGF) or $1 \mathrm{~h}$ after each treatment. Nuclear lysates (20 $\mu \mathrm{g}$ of total protein) were loaded into each lane of the gel, electrophoresed, and transferred to a PVDF membrane. (D) Phosphorylation levels of GSK3 $\beta$ at Ser ${ }^{9}$ were altered by treatment with bFGF, LiCl, and IWR-1. The cells were stimulated with bFGF (100 ng/mL), LiCl (1 $\mu \mathrm{M})$, or IWR-1 (1 $\mu \mathrm{M})$ for 30 min or $1 \mathrm{~h}$, and cell lysates (20 $\mu \mathrm{g})$ were loaded into each lane of a SDS-polyacrylamide gel, electrophoresed, and transferred to a PVDF membrane. Densitometry data for $\beta$-catenin (C) or pGSK3 $\beta$ Ser ${ }^{9}$ (D) from the blot shown in (E,F) were normalized to those of Lamin B or GSK3 $\beta$. The results are presented as fold changes relative to control fibroblasts grown in $5.5 \mathrm{mM}$ glucose-containing DMEM. Data represent mean values \pm the SE ( $n=5$ independent experiments; ${ }^{*} P<0.05$, ${ }^{* *} P<0.01$, ${ }^{* * *} P<0.001 ;$ Student's $t$-test). Con, control.

(P110 alpha) (Fukui et al., 2010) and neutralization of bFGF in the culture medium by a bFGF antibody reduced GSK3 $\beta$ Ser 9 phosphorylation levels (Supplementary Figure S2).

JNK is a downstream regulator of PI3K that is reportedly involved in bFGF-regulated fibroblast migration (Kanazawa et al., 2010). In next, role of JNK in regulation of GSK3 $\beta$ phosphorylation was tested. The results showed that significant decrease of $\beta$-catenin and pGSK3 $\beta \operatorname{Ser}^{9}$ were found in human fibroblasts treated with SP600125, a JNK inhibitor (Figures 3F-I). However, JNK phosphorylation levels did not differ with $\mathrm{LiCl}$ treatment (Figure 3J). Taken together, these results confirmed that bFGF/PI3K/JNK signaling acts at the upstream of GSK3 $\beta$.

\section{$\beta$-Catenin Is Critical for bFGF-Mediated Cell Migration}

To determine the role of $\beta$-catenin in fibroblast migration, $\beta$ catenin-specific siRNA was used to repress $\beta$-catenin expression (Singh et al., 2009). Because human foreskin fibroblasts are 


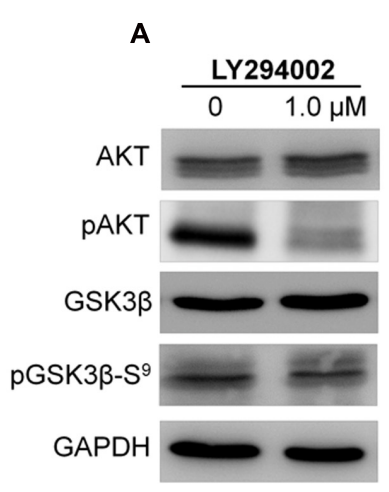

F

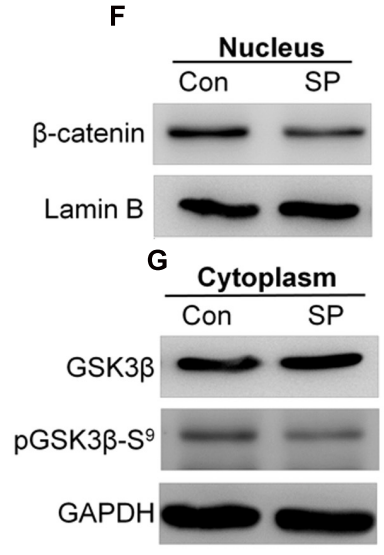

B

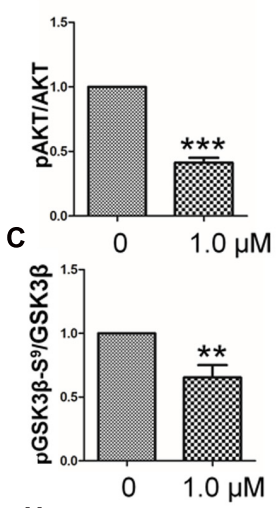

H
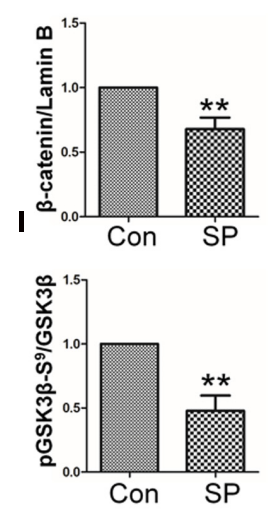
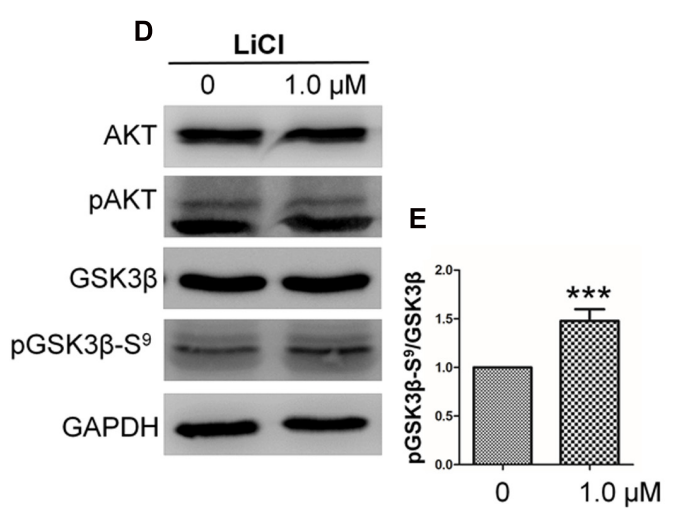

FIGURE 3 | Basic fibroblast growth factor activates the GSK3 $\beta / \beta$-catenin/WNT signaling pathway via the PI3K/JNK pathway. Human skin fibroblasts were treated for $1 \mathrm{~h}$ with the specific PI3K inhibitor, Ly294002 (1.0 $\mu \mathrm{M})$, the GSK3 $\beta$ inhibitor, LiCl (1.0 $\mu$ M), or solvent control. (A) Total cell lysates were then prepared and analyzed via Western blotting. Akt Ser ${ }^{473}$ and GSK3 $\beta$ Ser ${ }^{9}$ phosphorylation levels were blocked by Ly294002. (D) GSK3 $\beta$ Ser ${ }^{9}$ phosphorylation was increased by treatment with LiCl. (F) Nuclear $\beta$-catenin levels were increased by treatment with the JNK inhibitor, SP600125. (G) Phosphorylation levels of GSK3ß at $\mathrm{Ser}^{9}$ were reduced by treatment with SP600125 for $1 \mathrm{~h}$. (J) JNK phosphorylation was unchanged by LiCl treatment. Densitometry was performed on 3-4 Western blots (each representative of an independent experiment) per condition. Densitometry data for pAKT (B) or pGSK3 $\beta$ Ser ${ }^{9}$ (C) from the blots shown in (A) were normalized to those of AKT or GSK3 $\beta$. Densitometry data for pGSK3 $\beta$ Ser $^{9}$ (E) from the blot shown in (D) were normalized to those of GSK3 $\beta$. Densitometry data for nuclear $\beta$-catenin $\mathbf{( H )}$ from the blot shown in $\mathbf{( F )}$ were normalized to those of Lamin B. Densitometry data for pGSK3 $\beta$ Ser ${ }^{9} \mathbf{( I )}$ from the blot shown in $(\mathbf{F})$ were normalized to those of GSK3 $\beta$. The results are presented as fold changes relative to control fibroblasts grown in $5.5 \mathrm{mM}$ glucose-containing DMEM. Data represent mean values \pm the SE ( $n=5$ independent experiments; ${ }^{*} P<0.05,{ }^{* *} P<0.01,{ }^{* * *} P<0.001$; Student's $t$-test). Con, control.

active for a maximum of six generations or passages, they are not suitable for lentivirus-mediated transfection experiments. Thus, mouse NIH3T3 cells were employed for the siRNA experiments. The results showed that endogenous $\beta$-catenin levels in NIH3T3 cells were reduced by $\sim 50-95 \%$ following transfection (Supplementary Figure S3). Furthermore, $\beta$-catenin knock-down NIH3T3 cells exhibited a reduced rate of cell migration compared with control cells (Figure 4A), and $\mathrm{LiCl}$ or IWR-1 treatment exerted no effect on the $\beta$-catenin knock-down cell line (Supplementary Figure S4). Also, bFGF administration only slightly increased the migration rate of $\beta$-catenin knockdown cells (Figure 4B), indicating that $\beta$-catenin is necessary to promote bFGF-mediated fibroblast migration.

\section{$\beta$-Catenin Activates FGFs}

RNA sequencing analysis was performed to examine transcriptome changes in $\beta$-catenin knock-down NIH3T3 cells. We found that 411 genes were differentially expressed in the $\beta$-catenin knock-down group. Among them, 201 genes were up-regulated, and 210 genes were down-regulated $(P<0.05$ and fold change $>2.0$ ) (Supplementary Table S2). These findings were further validated from statistical outcomes in tests for association with biological process GO terms (Supplementary Figure S5). Pathway analysis was used to determine the significance of the differentially expressed gene sets according to KEGG, which demonstrated that six up-regulated and six down-regulated clusters were significantly enriched by silencing of $\beta$-catenin (Figure 5). Interestingly, FGF21 as well as $b F G F$ expression levels were sensitive to $\beta$-catenin. According to the expression patterns summarized in Figure 6A, bFGF and FGF21 were reduced significantly as well as Wnt pathway-related gene FZD8, and Wnt3a was increased by $\beta$-catenin-specific siRNA.

FGF21, a secreted protein (Badman et al., 2007), which is the most studied family member, and has been reported to be preferentially expressed in the liver early in development (Nishimura et al., 2000). However, recent studies have reported 


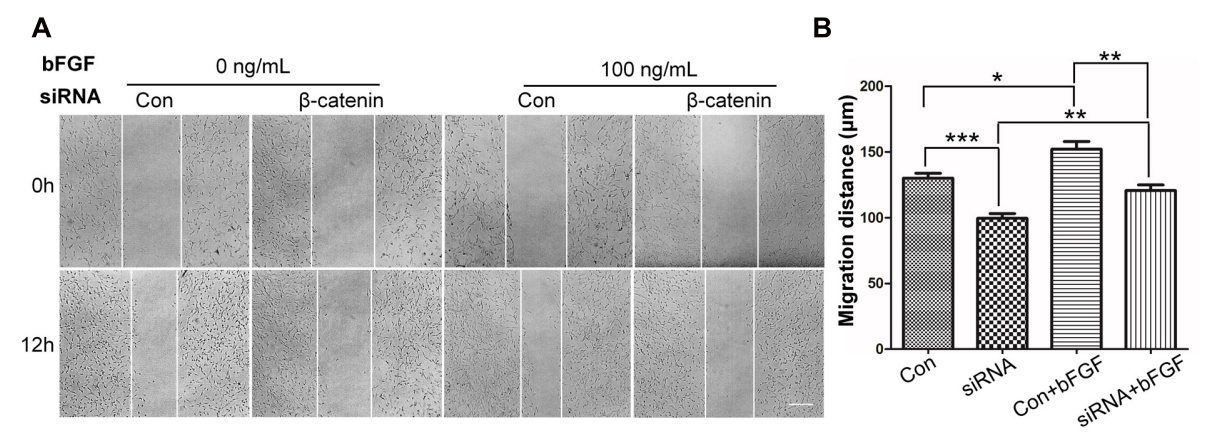

B

FIGURE 4 | Effect of siRNA-mediated inhibition of $\boldsymbol{\beta}$-catenin in NIH3T3 cell migration. (A) A wound healing assay was performed in cells transfected with scrambled control siRNA or $\beta$-catenin siRNA with or without bFGF (100 ng/mL). The wounded cell monolayers were photographed at 0 and $12 \mathrm{~h}$ after the treatment. White vertical lines indicate the borders of the wound area. Bar $=500 \mu \mathrm{m}$. (B) Cell migration distances shown in (A) were measured and plotted $\left({ }^{*} P<0.05\right.$,

${ }^{* *} P<0.01,{ }^{* * *} P<0.001$; Student's $t$-test). Con, control.

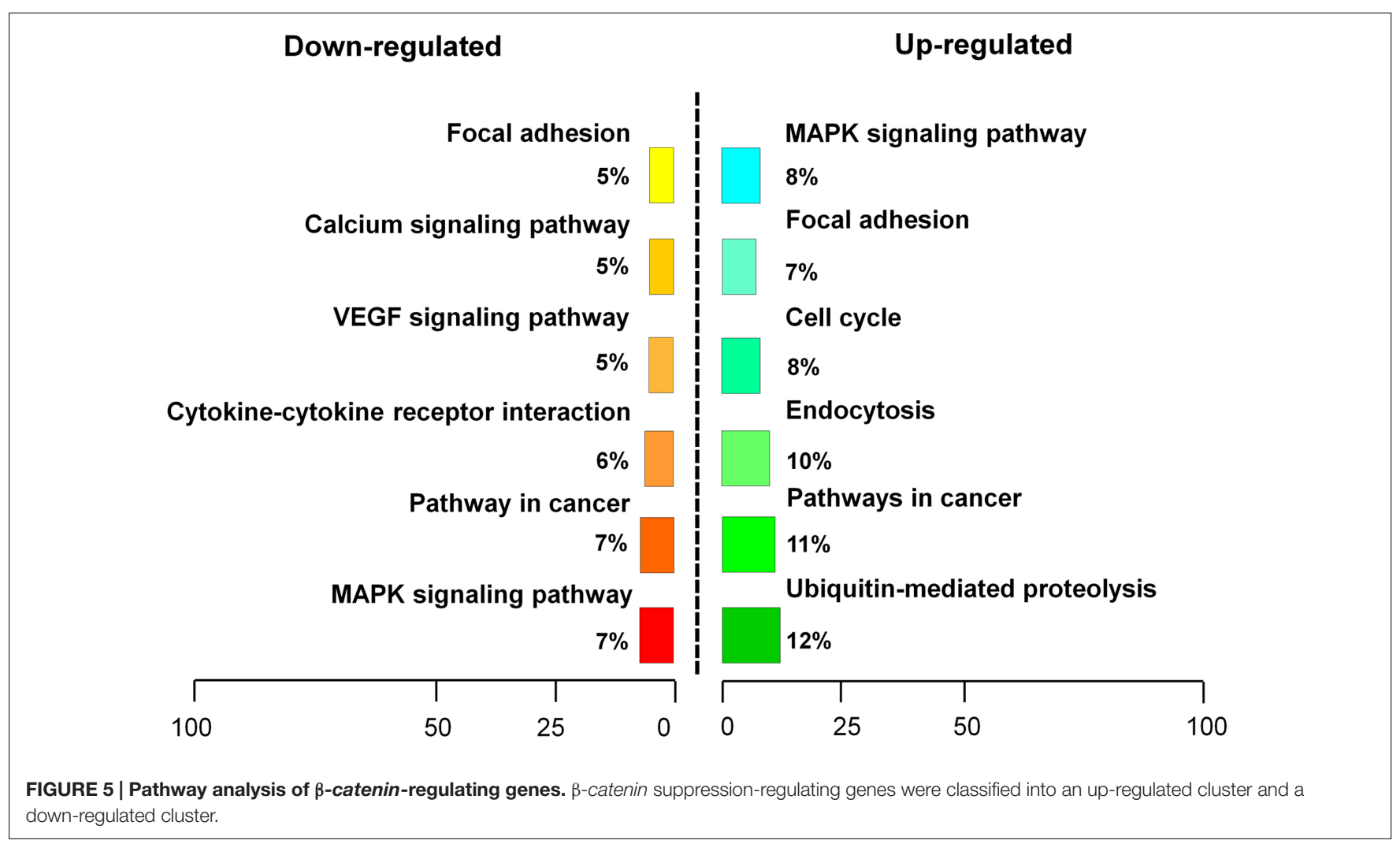

that FGF21 production is inducible by starvation or drug administration, and revealed its diverse functions in glucose homeostasis and protection of the liver and heart from injury (Lin et al., 2013, 2014; Liang et al., 2014).

To further understand the influence of FGF21 in cell migration, wound healing scratch assay and Western blot were performed on NIH3T3 cells with FGF21 treatment. The results showed that FGF21 promoted cell migration of fibroblasts and $\beta$-catenin-suppressed NIH3T3 cells (Figures 6B,C; Supplementary Figures S6A-C). In addition, Western blot analysis showed that exogenous FGF21 treatment increased AKT phosphorylation levels (Figures 6D,E), and neutralization of
FGF21 in the culture medium by a FGF21 antibody reduced GSK $3 \beta$ Ser$^{9}$ phosphorylation levels to the same extent as bFGF (Supplementary Figures S6D,E). Taken together, these results suggest that FGF21 acted similarly to bFGF, therefore, it is necessary to further examine its roles in fibroblast cell migration.

\section{A Feedback Activation of bFGF via the Wnt/ $\beta$-Catenin Pathway}

Wnt3a, known as a main sign of activation of Canonical Wnt pathway, was assayed by ELISA (Shimizu et al., 1997). As shown in Figure 7A, Wnt3a in fibroblasts is increased upon 

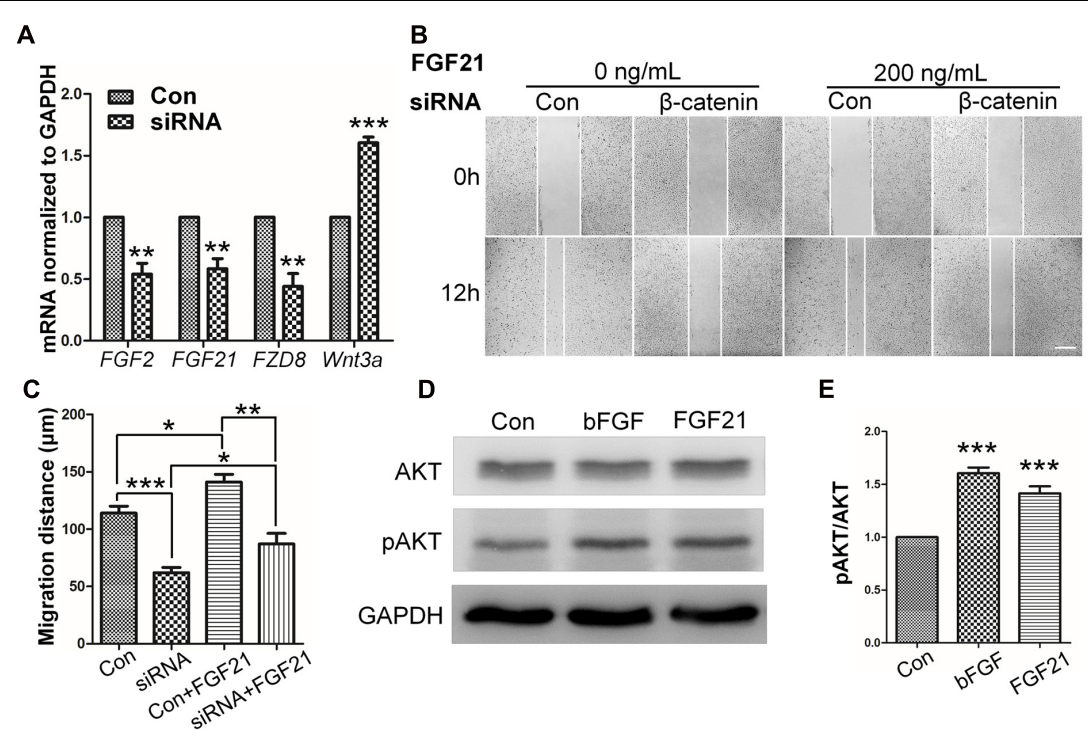

D

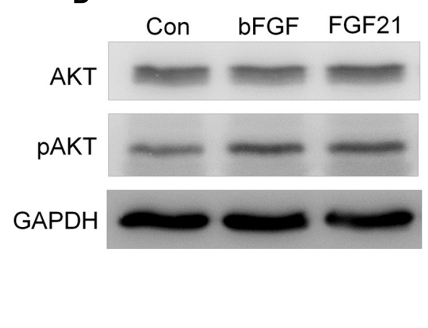

E

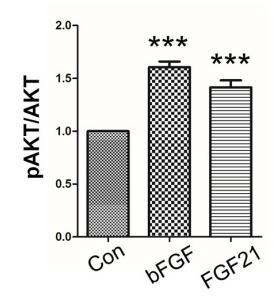

FIGURE 6 | Role of FGF and $\beta$-catenin in fibroblast migration and downstream regulations. (A) qRT-PCR was performed to monitor the mRNA levels of FGF2, FGF21, FZD8, and Wnt3a. GAPDH was used as an internal control. Data represent mean values \pm the SE of five replicates $(* * P<0.01, * * * P<0.0001$ versus the untreated control group; Student's $t$-test). (B) A wound healing assay was performed with or without FGF21 treatment (200 ng/mL), and the wounded cell monolayers were photographed 0 and $12 \mathrm{~h}$ later. White vertical lines indicate the borders of the wound area. Bar $=500 \mu \mathrm{m}$. (C) Cell migration distances were measured based on the data shown in (B). Data represent mean values \pm the SE of five replicates $\left({ }^{*} P<0.05\right.$, ${ }^{* *} P<0.01$, ${ }^{* * *} P<0.0001$; Student's $t$-test). (D) Western blotting was performed to analyze the protein levels of pAKT after 30 min treatment of fibroblasts with bFGF (100 ng/mL) or FGF21 (200 ng/mL). Densitometry data for PAKT (E) from the blot shown in (D) were normalized to those of AKT. All experiments were performed $24 \mathrm{~h}$ after application of $5 \mu \mathrm{g} / \mathrm{mL}$ mitomycin-C (a cell proliferation inhibitor). Data represent mean values \pm the SE $(n=5$ independent experiments; *** $P<0.0001$ versus untreated control; Student's t-test). Con, control.
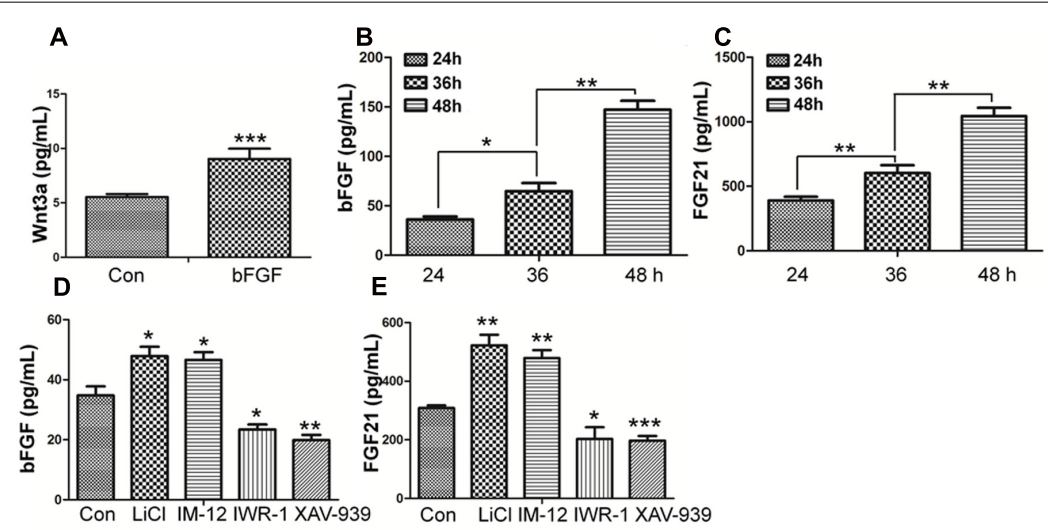

FIGURE 7 | Effect of bFGF on the secretion of Wnt3a and the Effects of normal condition and Wnt pathway agonists and antagonists on the secretion of bFGF and FGF21 in fibroblasts by ELISA. (A) The cultured cells were treated with $100 \mathrm{ng} / \mathrm{mL}$ bFGF for $24 \mathrm{~h}$, and the cell supernatants were collected to detect Wnt3a-secreted level. The results are presented the secretion of Wnt3a in fibroblasts is increased upon bFGF stimulation for 24 h. (B,C) The cells were cultured normally, and the cultured supernatants were collected after 24, 36, 48 h, respectively. The results are presented the release of bFGF and FGF21 in fibroblasts grown in $5.5 \mathrm{mM}$ glucose-containing DMEM for $24 \mathrm{~h}$. (D,E) The cultured cells were treated with 1.0 $\mu \mathrm{M}$ LiCl, 0.5 $\mu \mathrm{M}$ IM-12, 1.0 IWR-1, 0.5 $\mu$ M XAV-939 or vehicle for $24 \mathrm{~h}$, and the cell supernatants were collected to test the bFGF and FGF21 release. Elisa analysis showed that the secretion of bFGF and FGF21 in fibroblasts is up regulated upon $\mathrm{LiCl}$ and IM-12 stimulation for $24 \mathrm{~h}$, while down regulated upon IWR-1 and XAV-939. Data represent mean values \pm the SE $(n=5$ independent experiments; ${ }^{*} P<0.05,{ }^{* *} P<0.01,{ }^{* * *} P<0.001$; Student's $t$-test). Con, control.

bFGF stimulation, which further confirmed that Wnt signaling output was increased by bFGF treatment. On the other hand, the secretion of bFGF and FGF21 were analyzed under normal condition, Wnt pathway agonist and antagonist treatment, respectively (Figures $\mathbf{7 B}-\mathbf{E}$ ). The results showed that the $\mathrm{LiCl}$ and IM-12 treatment increased secretion of bFGF and FGF21, but decreased by IWR-1 and XAV-939 treatment. Besides, cell migration was reduced by addition of neutralizing antibody of bFGF and FGF21 in the culture medium (Supplementary Figure S7A). Moreover, BGJ398, an inhibitor of FGFR (Costa 


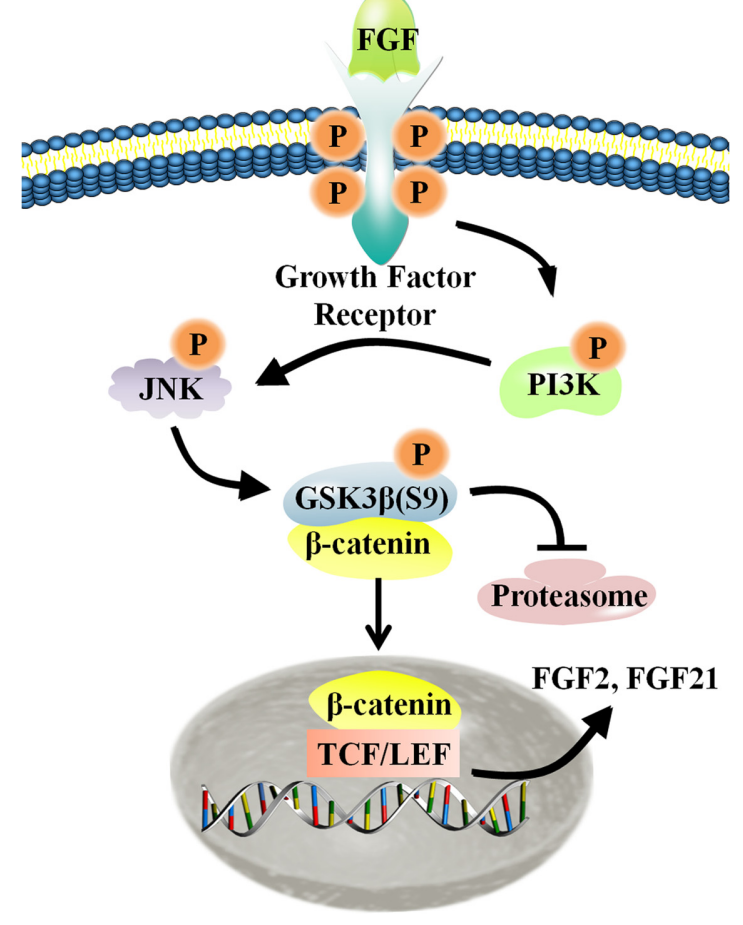

FIGURE 8 | Schematic representation of the crosstalk between the Wnt and FGF signaling pathways in fibroblasts. For additional explanation, please see text.

et al., 2014), slowed migration dramatically, which suggested that a feedback regulatory loop between bFGF (FGF21) and Wnt signaling acting through $\beta$-catenin in skin fibroblasts.

\section{$\beta$-Catenin Directly Activates FGF21 Transcription but not of bFGF}

Basic fibroblast growth factor and FGF21 promoter sequences analysis showed that two and three putative TCF/LEF binding motifs (AGAAAG) (Schuijers et al., 2014), respectively, were appeared within $3 \mathrm{~kb}$ of bFGF and FGF21 promoters. Also, $\beta$-catenin interacts with TCF/LEF, and activates the transcription of Wnt signaling genes after $\beta$-catenin accumulated in the nucleus (Gordon and Nusse, 2006). Therefore, the possibility of $\beta$-catenin complex binding to the bFGF and FGF21 promoters were examined. The two putative binding motifs are located 374 and 518 bp downstream of the start codon of $b F G F$, respectively, while three putative binding motifs are located 976, 1062 and $2269 \mathrm{bp}$ downstream of the start codon of FGF21, respectively (Supplementary Figure S8A). To examine whether $\beta$-catenin complex directly binds to the putative motifs, ChIP assays were performed using $\beta$-catenin antibody. The immunoprecipitated DNA fragments were amplified by five primer pairs which could span P1-P5 regions located within bFGF and FGF21 promoters (Supplementary Figure S8A). The ChIP-PCR data was normalized to input DNA and the results showed that $\beta$-catenin complex bound to the P4 and P5 regions in the promoters of
FGF21 gene but not of P1-P3 regions in the promoters of bFGF gene (Supplementary Figure S8B).

\section{DISCUSSION}

Migration of dermal fibroblasts is crucial for skin wound repair. bFGF is a member of the FGF family of growth factors, and is an efficacious promoter of fibroblast migration. Recent work showed that bFGF activates the PI3K/Rac1/JNK pathway and NFKB-JNK pathway to accelerate cell migration (Xuan et al., 2014, 2016). However, up until now, little information has been available regarding bFGF-meditated control of signaling pathways. Here, we utilized RNA sequencing analysis to demonstrate that Wnt $/ \beta$-catenin signaling genes are regulated by bFGF. Further analyses indicated that PI3K and JNK function upstream of GSK3 $\beta$ and $\beta$-catenin, two principal regulators of Wnt signaling. As the phosphorylation of GSK $3 \beta$ might be indirectly stimulated by MAP kinase, including JNK, we investigated the possibility of a JNK mediated increase in the GSK3 $\beta$ phosphorylation level in bFGF treated fibroblasts (Stambolic and Woodgett, 1994). Coincidentally, exogenous bFGF-mediated stimulation of fibroblasts apparently activated the PI3K/JNK pathway, which in turn phosphorylated GSK3 $\beta$ and positively regulates $\beta$-catenin shuttling between the cytoplasm and the nucleus (Figure 8). The translocation of $\beta$-catenin from the cytoplasm into the nucleus can then activate the downstream transcriptional factors, TCF/LEF, promoting the transcription of Wnt target genes such as FZD8 and Wnt3a, and also inducing the expression of $b F G F$ and FGF21.

Basic fibroblast growth factor, $\mathrm{LiCl}$, and IM-12 significantly accelerated cell migration. On the other hand, the Wnt inhibitors, IWR-1 and XAV-939, delayed cell migration, and bFGF somewhat attenuated the effects from IWR-1, which is consistent with previous reports (Lam et al., 2011). For LiCl, millimolar concentrations were applied in many research, which play significant roles to study cell proliferation, differentiation, migration (Teng et al., 2010; Azimian-Zavareh et al., 2012). In contrast to the above reports, micromolar concentrations of $\mathrm{LiCl}$ were used in some studies, which indicated that low concentrations of $\mathrm{LiCl}$ could be effective therapeutic doses in certain conditions (Nakamura et al., 2003; Zarse et al., 2011; Huang et al., 2015; Erguven et al., 2016; Xu et al., 2016). For instance, Erguven et al found that low concentrations of $\mathrm{LiCl}$ significantly increased cell number, while high concentrations of $\mathrm{LiCl}$ significantly decreased cell number. In our research, $\mathrm{LiCl}$ was tested at a concentration ranging from 0.5 to $10 \mu \mathrm{M}$ in the cell migration. Base on the results, $1 \mu \mathrm{M} \mathrm{LiCl}$ was the more appropriate concentration to enhance migration by inhibited phosphorylation of GSK3 $\beta$ at Ser9, which results in $\beta$-catenin stabilization and leads to enhanced Wnt signaling (Fei et al., 2011). Therefore, $1 \mu \mathrm{M} \mathrm{LiCl}$ was applied for further experiments.

At the protein level, bFGF activates the PI3K/JNK pathway, leading to phosphorylation of GSK3 $\beta$ at Ser ${ }^{9}$. Normally, GSK3 $\beta$ maintains low cytoplasmic expression of $\beta$-catenin via phosphorylation. Phosphorylated $\beta$-catenin can be ubiquitinated through the F-box-containing protein, beta-transducin repeat 
containing protein, an ubiquitin E3 ligase, and then degraded by the proteasome (Aberle et al., 1997; Kitagawa et al., 1999). Thus, inactivation of GSK $3 \beta$ stabilizes $\beta$-catenin and increases its nuclear content. As described above, bFGF-mediated activation of Wnt signaling was apparent herein both in vitro and in vivo, triggering the migration of fibroblasts and concomitant wound healing. In our previous work, we found that ubiquitinationrelated genes (OTUB1, Peli1, UBFD1) were altered by bFGF stimulation observed by RNA-Seq assay, indicating that bFGF might not only inactivate GSK3 $\beta$, but also reduce proteasomemediated degradation of $\beta$-catenin (Xuan et al., 2016).

Also, previous studies found that $\beta$-catenin inhibits the proliferation of murine melanoblasts and human melanoma cells (Chien et al., 2009; Luciani et al., 2011), and may play conflicting roles in the metastatic spread of melanoma, repressing migration while promoting metastasis (Gallagher et al., 2013). However, in our study, $\beta$-catenin suppression significantly delayed the migration of NIH3T3 cells, supporting a pro-migratory role for $\beta$-catenin. Furthermore, IWR treatment showed a similar effect to $\beta$-catenin knock-down. Interestingly, bFGF partially overcame the inhibitory actions of both $\beta$ catenin repression and IWR-1. Moreover, a prior study showed that $\beta$-catenin promotes migration, invasion, and proliferation in colorectal, liver, lung, and breast cancers (Gallagher et al., 2013). Combined with our observations, it is concluded that the pro-migratory effect induced by bFGF was mainly mediated by $\mathrm{Wnt} / \beta$-catenin pathway, notwithstanding the effect contributed by other signaling pathways (Xuan et al., 2014, 2016).

Notably, FGF21 expression levels were negatively influenced by the down-regulation of $\beta$-catenin, similar to $b F G F$ transcription levels. FGF21 primarily activates FGFR1c, an isoform of FGFR1, and exhibits a preference for the $\beta$-klotho co-receptor (Yie et al., 2012; Belov and Mohammadi, 2013). In the present study, FGF21, like bFGF, promoted normal skin fibroblast migration, and increased the migration speed of $\beta$-catenin-suppressing fibroblasts. $\beta$-klotho expression was also detected in skin fibroblasts (data not shown), supporting a role for FGF21 in the skin wound healing. In addition, Western blot analysis showed that exogenous FGF21 treatment activated Wnt signaling in fibroblasts to the same extent as exogenous bFGF. These results indicate that acceleration of fibroblast migration through the PI3K/JNK/GSK3 $\beta / \beta$-catenin signaling cascade acts in a feedback loop to regulate the expression of both $b F G F$ and FGF21. However, promoter sequence analysis revealed that the putative $\beta$-catenin-TCF4 transcription factor complex binding motifs appeared in the promoter of FGF21, but not in bFGF (Matsumoto et al., 2014). For further study, it would be extremely interesting to find the reason that $\beta$-catenin did not bind the P1-P3 regions in the promoters of bFGF. In addition, TCF $4 / \beta$-catenin complex directly regulate FGF21 transcription by ChIP assay, implying that constitutive activation of FGF21 might be important in cell migration process as well as bFGF. Furthermore, FGF21 treatments still accelerated the migration of $\beta$-catenin-suppressing fibroblast cells comparing with that of the control groups. It may be attributed to the incomplete suppression of endogenous $\beta$-catenin or activation of other downstream signaling, which is able to partially rescue the cell migration.

Based on the present results and previous works, our analyses provide evidence for the following conclusions: (1) Wnt signaling plays a role in FGF-mediated fibroblast migration; (2) PI3K/JNK acts at the downstream of FGF signaling to positively regulate GSK3 $\beta / \beta$-catenin activity; (3) a new role for FGF21 is identified in fibroblast migration; and (4) $\beta$-catenin also acts downstream of FGF signaling, but in turn activates transcription of $b F G F$ and FGF21, two FGF family member genes. Treatment with bFGF and FGF21 partially recovered the delayed cell migration rates in response to reduced $\beta$-catenin expression, suggesting that $\beta$-catenin-facilitated promotion of cell migration stems from transcriptional activation of $b F G F$ and FGF21, at least in part. Nevertheless, because $\beta$-catenin also regulates the transcription of a number of other genes, further analyses are required to identify additional components involved in fibroblast migration during wound healing.

\section{AUTHOR CONTRIBUTIONS}

XW, YX, YZ, CS, and XL proposed and designed experiments and/or interpreted data; YZ, CS, WHC, YS, and LC performed experiments; HW and NS contributed essential reagents and tools; WTC, TW, CN, and JS participated in writing; WTC and JYS contributed essential reagents and tools and gave conceptual advice; $\mathrm{ZZ}$ gave conceptual advice and interpreted data; YX contributed essential reagents and tools, gave conceptual advice and critically revised the paper; LJ supervised the project, interpreted data and wrote the paper.

\section{ACKNOWLEDGMENTS}

We thank the members of LC Biotech for performing the RNA sequencing assay, and this work was supported by grants from the National Nature Science Foundation of China (81371753, 81573069,81673077 , and 81600304), the Technology Program of Wenzhou (Y20160001 and Y20160003) and Scientific Research Starting Foundation (QTJ15015).

\section{SUPPLEMENTARY MATERIAL}

The Supplementary Material for this article can be found online at: http://journal.frontiersin.org/article/10.3389/fphar. 2017.00032/full\#supplementary-material 


\section{REFERENCES}

Aberle, H., Bauer, A., Stappert, J., Kispert, A., and Kemler, R. (1997). beta-catenin is a target for the ubiquitin-proteasome pathway. EMBO J. 16, 3797-3804. doi: $10.1093 /$ emboj/16.13.3797

Aman, A., and Piotrowski, T. (2008). Wnt/ $\beta$-catenin and fgf signaling control collective cell migration by restricting chemokine receptor expression. Dev. Cell 11, 749-761. doi: 10.1016/j.devcel.2008.10.002

Amini-Nik, S., Cambridge, E., Yu, W., Guo, A., Whetstone, H., Nadesan, P., et al. (2014). $\beta$-catenin-regulated myeloid cell adhesion and migration determine wound healing. J. Clin. Invest. 124, 2599-2610. doi: 10.1172/JCI62059

Azimian-Zavareh, V., Hossein, G., and Janzamin, E. (2012). Effect of lithium chloride and antineoplastic drugs on survival and cell cycle of androgendependent prostate cancer LNCap cells. Indian J. Pharmacol. 44, 714-721. doi: 10.4103/0253-7613.103265

Badman, M. K., Pissios, P., Kennedy, A. R., Koukos, G., Flier, J. S., and MaratosFlier, E. (2007). Hepatic fibroblast growth factor 21 is regulated by PPARalpha and is a key mediator of hepatic lipid metabolism in ketotic states. Cell Metab. 5, 426-437. doi: 10.1016/j.cmet.2007.05.002

Belov, A. A., and Mohammadi, M. (2013). Molecular mechanisms of fibroblast growth factor signaling in physiology and pathology. Cold Spring Harb. Perspect. Biol. 5, a015958. doi: 10.1101/cshperspect.a015958

Bergmann, C., Akhmetshina, A., Dees, C., Palumbo, K., Zerr, P., Beyer, C., et al. (2011). Inhibition of glycogen synthase kinase $3 \beta$ induces dermal fibrosis by activation of the canonical Wnt pathway. Ann. Rheum. Dis. 70, 2191-2198. doi: 10.1136/ard.2010.147140

Bianchi, M., De Lucchini, S., Marin, O., Turner, D., Hanks, S., and Villa-Moruzzi, E. (2005). Regulation of FAK Ser-722 phosphorylation and kinase activity by GSK3 and PP1 during cell spreading and migration. Biochem. J. 391, 359-370. doi: 10.1042/BJ20050282

Boku, S., Nakagawa, S., Toda, H., Kato, A., Takamura, N., Omiya, Y., et al. (2013). ROCK2 regulates bFGF-induced proliferation of SH-SY5Y cells through GSK$3 \beta$ and $\beta$-catenin pathway. Brain Res. 1492, 7-17. doi: 10.1016/j.brainres.2012. 11.034

Brack, A. S., Conboy, M. J., Roy, S., Lee, M., Kuo, C. J., Keller, C., et al. (2007). Increased Wnt signaling during aging alters muscle stem cell fate and increases fibrosis. Science 317, 807-810. doi: 10.1126/science.1144090

Cai, T., Sun, D. Q., Duan, Y., Wen, P., Dai, C. S., Yang, J. W., et al. (2016). WNT/ $\beta$-catenin signaling promotes VSMCs to osteogenic transdifferentation and calcification through directly modulating Runx2 gene expression. Exp. Cell Res. 345, 206-217. doi: 10.1016/j.yexcr.2016.06.007

Chien, A. J., Moore, E. C., Lonsdorf, A. S., Kulikauskas, R. M., Rothberg, B. G., Berger, A. J., et al. (2009). Activated Wnt/beta-catenin signaling in melanoma is associated with decreased proliferation in patient tumors and a murine melanoma model. Proc. Natl. Acad. Sci. U.S.A. 27, 1193-1198. doi: 10.1073/ pnas.0811902106

Clevers, H. (2006). Wnt/ $\beta$-catenin signaling in development and disease. Cell 127, 469-480. doi: 10.1016/j.cell.2006.10.018

Clevers, H., and Nusse, R. (2012). Wnt/beta-catenin signaling and disease. Cell 8, 1192-1205. doi: 10.1016/j.cell.2012.05.012

Cohen, P., and Frame, S. (2001). The renaissance of GSK3. Nat. Rev. Mol. Cell Biol. 2, 769-776. doi: 10.1038/35096075

Consortium, G. O. (2006). The gene ontology (GO) project in 2006. Nucleic Acids Res. 34, D322-D326. doi: 10.1093/nar/gkj021

Costa, C., Ebi, H., Martini, M., Beausoleil, S. A., Faber, A. C., Jakubik, C. T., et al. (2014). Measurement of PIP3 levels reveals an unexpected role for p110 $\beta$ in early adaptive responses to p110 $\alpha$-specific inhibitors in luminal breast cancer. Cancer Cell 27, 97-108. doi: 10.1016/j.ccell.2014.11.007

Draghici, S., Khatri, P., Tarca, A. L., Amin, K., Done, A., Voichita, C., et al. (2007). A systems biology approach for pathway level analysis. Genome Res. 17, 1537-1545. doi: 10.1101/gr.6202607

Dunnick, J., Brix, A., Cunny, H., Vallant, M., and Shockley, K. (2012). Characterization of polybrominated diphenyl ether toxicity in wistar han rats and use of liver microarray data for predicting disease susceptibilities. Toxicol. Pathol. 40, 93-106. doi: 10.1177/0192623311429973

Dupuy, D., Bertin, N., Hidalgo, C. A., Venkatesan, K., Tu, D., Lee, D., et al. (2007). Genome-scale analysis of in vivo spatiotemporal promoter activity in Caenorhabditis elegans. Nat. Biotechnol. 25, 663-668. doi: 10.1038/nbt1305
Dvorak, P., and Hampl, A. (2005). Basic fibroblast growth factor and its receptors in human embryonic stem cells. Folia Histochem. Cytobiol. 43, 203-208.

Engelman, J. A., Luo, J., and Cantley, L. C. (2006). The evolution of phosphatidylinositol 3-kinases as regulators of growth and metabolism. Nat. Rev. Genet. 7, 606-619. doi: 10.1038/nrg1879

Enoch, S., and Price, P. (2004). Cellular, molecular and biochemical differences in the pathophysiology of healing between acute wounds, chronic wounds and wounds in the aged. World Wide Wounds. Available at: http://www.worldwidewounds.com/2004/august/Enoch/Pathophysiology-OfHealing.html

Epstein, F. H., Singer, A. J., and Clark, R. A. (1999). Cutaneous wound healing. New England J. Med. 341, 738-746. doi: 10.1056/NEJM199909023411006

Erguven, M., Oktem, G., Kara, A. N., and Bilir, A. (2016). Lithium chloride has a biphasic effect on prostate cancer stem cells and a proportional effect on midkine levels. Oncol. Lett. 12, 2948-2955.

Etienne-Manneville, S., and Hall, A. (2003). Cdc42 regulates GSK-3 $\beta$ and adenomatous polyposis coli to control cell polarity. Nature 421, 753-756. doi: 10.1038 /nature01423

Fei, Y., Xiao, L., Doetschman, T., Coffin, D. J., and Hurley, M. M. (2011). Fibroblast growth factor 2 stimulation of osteoblast differentiation and bone formation is mediated by modulation of the Wnt signaling pathway. J. Biol. Chem. 25, 40575-40583. doi: 10.1074/jbc.M111.274910

Fukui, M., Choi, H. J., and Zhu, B. T. (2010). Mechanism for the protective effect of resveratrol against oxidative stress-induced neuronal death. Free Radic. Biol. Med. 1, 800-813. doi: 10.1016/j.freeradbiomed.2010.06.002

Gallagher, S. J., Rambow, F., Kumasaka, M., Champeval, D., Bellacosa, A., Delmas, V., et al. (2013). Beta-catenin inhibits melanocyte migration but induces melanoma metastasis. Oncogene 32, 2230-2238. doi: 10.1038/onc.2012. 229

Gordon, M. D., and Nusse, R. (2006). Wnt signaling: multiple pathways, multiple receptors, and multiple transcription factors. J. Biol. Chem. 11, 22429-22433. doi: 10.1074/jbc.R600015200

Harris, E. S., and Nelson, W. J. (2010). Adenomatous polyposis coli regulates endothelial cell migration independent of roles in $\beta$-Catenin signaling and cell-cell adhesion. Mol. Biol. Cell 21, 2611-2623. doi: 10.1091/mbc.E10-030235

Hu, Y., Poopalasundaram, S., Graham, A., and Bouloux, P. M. (2013). GnRH neuronal migration and olfactory bulb neurite outgrowth are dependent

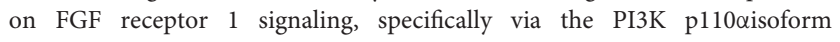
in chick embryo. Endocrinology 154, 388-399. doi: 10.1210/en.20121555

Huang, C. K., Yu, T., de la Monte, S. M., Wands, J. R., Derdak, Z., and Kim, M. (2015). Restoration of Wnt/beta-catenin signaling attenuates alcoholic liver disease progression in a rat model. J. Hepatol. 63, 191-198. doi: 10.1016/j.jhep. 2015.02.030

Jeong, M. H., Ho, S. M., Vuong, T. A., Jo, S. B., Liu, G. Z., Aaronson, S. A., et al. (2014). Cdo supresses canonical Wnt signaling via interaction with Lrp6 thereby promoting neuronal differentiation. Nat. Commun. 9, 5455-5468. doi: $10.1038 /$ ncomms6455

Kanazawa, S., Fujiwara, T., Matsuzaki, S., Shingaki, K., Taniguchi, M., Miyata, S., et al. (2010). bFGF regulates PI3-kinase-Rac1-JNK pathway and promotes fibroblast migration in wound healing. PLOS ONE 5:e12228. doi: 10.1371/ journal.pone.0012228

Kitagawa, M., Hatakeyama, S., Shirane, M., Matsumoto, M., Ishida, N., Hattori, K., et al. (1999). An F-box protein, FWD1, mediates ubiquitin-dependent proteolysis of beta-catenin. EMBO J. 4, 2401-2410. doi: 10.1093/emboj/18.9. 2401

Klein, P. S., and Melton, D. A. (1996). A molecular mechanism for the effect of lithium on development. Proc. Natl. Acad. Sci. U.S.A. 93, 8455-8459. doi: 10.1073/pnas.93.16.8455

Lam, A. P., Flozak, A. S., Russell, S., Wei, J., Jain, M., Mutlu, G. M., et al. (2011). Nuclear $\beta$-catenin is increased in systemic sclerosis pulmonary fibrosis and promotes lung fibroblast migration and proliferation. Am. J. Respir. Cell Mol. Biol. 45, 915-922. doi: 10.1165/rcmb.2010-0113OC

Liang, Q., Zhong, L., Zhang, J., Wang, Y., Bornstein, S. R., Triggle, C. R., et al. (2014). FGF21 maintains glucose homeostasis by mediating the cross talk between liver and brain during prolonged fasting. Diabetes Metab. Res. Rev. 63, 4064-4075. doi: 10.2337/db14-0541 
Lin, Z., Tian, H., Lam, K. S., Lin, S., Hoo, R. C., Konishi, M., et al. (2013). Adiponectin mediates the metabolic effects of FGF21 on glucose homeostasis and insulin sensitivity in mice. Cell Metab. 17, 779-789. doi: 10.1016/j.cmet. 2013.04.005

Lin, Z., Wu, F., Lin, S., Pan, X., Jin, L., Lu, T., et al. (2014). Adiponectin protects against acetaminophen-induced mitochondrial dysfunction and acute liver injury by promoting autophagy in mice. J. Hepatol. 61, 825-831. doi: 10.1016/j. jhep.2014.05.033

Luciani, F., Champeval, D., Herbette, A., Denat, L., Aylaj, B., Martinozzi, S., et al. (2011). Biological and mathematical modeling of melanocyte development. Development 138, 3943-3954. doi: 10.1242/dev.067447

Martin, P. (1997). Wound healing-aiming for perfect skin regeneration. Science 276, 75-81. doi: 10.1126/science.276.5309.75

Matsumoto, S., Fujii, S., Sato, A., Ibuka, S., Kagawa, Y., Ishii, M., et al. (2014). A combination of Wnt and growth factor signaling induces Arl4c expression to form epithelial tubular structures. EMBO J. 1, 702-718. doi: 10.1002/embj. 201386942

Moon, R. T., Kohn, A. D., De Ferrari, G. V., and Kaykas, A. (2004). WNT and $\beta$-catenin signalling: diseases and therapies. Nat. Rev. Genet. 5, 691-701. doi: $10.1038 / \mathrm{nrg} 1427$

Nakamura, T., Sano, M., Song, Y. Z., and Schneider, M. D. (2003). A Wnt-and betacatenin-dependent pathway for mammalian cardiac myogenesis. Proc. Natl. Acad. Sci. U.S.A. 100, 5834-5839. doi: 10.1073/pnas.0935626100

Nishimura, T., Nakatake, Y., Konishi, M., and Itoh, N. (2000). Identification of a novel FGF, FGF-21, preferentially expressed in the liver. Biochim. Biophys. Acta. 1492, 203-206. doi: 10.1016/S0167-4781(00)00067-1

Pazyar, N., Yaghoobi, R., Rafiee, E., Mehrabian, A., and Feily, A. (2014). Skin wound healing and phytomedicine: a review. Skin Pharmacol. Physiol. 27, 303-310. doi: 10.1159/000357477

Salic, A., Lee, E., Mayer, L., and Kirschner, M. W. (2000). Control of $\beta$-catenin stability: reconstitution of the cytoplasmic steps of the wnt pathway in Xenopus egg extracts. Mol. Cell 5, 523-532. doi: 10.1016/S1097-2765(00) 80446-3

Schuijers, J., Mokry, M., Hatzis, P., Cuppen, E., and Clevers, H. (2014). Wntinduced transcriptional activation is exclusively mediated by TCF/LEF. EMBO J. 33, 146-156. doi: 10.1002/embj.201385358

Shimizu, H., Julius, M. A., Giarre, M., Zheng, Z. L., and Brown, A. M. (1997). Transformation by Wnt family proteins correlates with regulation of $\beta$-catenin. Cell Growth Differ. 8, 1349-1358.

Shtutman, M., Zhurinsky, J., Simcha, I., Albanese, C., D’Amico, M., Pestell, R., et al. (1999). The cyclin D1 gene is a target of the beta-catenin/LEF-1 pathway. Proc. Natl. Acad. Sci. U.S.A. 11, 5522-5527. doi: 10.1073/pnas.96.10. 5522

Singh, R., Bhasin, S., Braga, M., Artaza, J. N., Pervin, S., Taylor, W. E., et al. (2009). Regulation of myogenic differentiation by androgens: cross talk between androgen receptor/ $\beta$-catenin and follistatin/transforming growth factor- $\beta$ signaling pathways. Endocrinology 150, 1259-1268. doi: 10.1210/en. 2008-0858

Stambolic, V., and Woodgett, J. R. (1994). Mitogen inactivation of glycogen synthase kinase- 3 beta in intact cells via serine 9 phosphorylation. Biochem. J. 303(Pt. 3), 701-704. doi: 10.1042/bj3030701
Sun, T., Rodriguez, M., and Kim, L. (2009). Glycogen synthase kinase 3 in the world of cell migration. Dev. Growth Differ. 51, 735-742. doi: 10.1111/j.1440-169X. 2009.01141.x

Teng, Y., Wang, X., Wang, Y., and Ma, D. (2010). Wnt/beta-catenin signaling regulates cancer stem cells in lung cancer A549 cells. Biochem. Biophys. Res. Commun. 12, 373-379. doi: 10.1016/j.bbrc.2010.01.028

Thamm, O. C., Theodorou, P., Stuermer, E., Zinser, M. J., Neugebauer, E. A., Fuchs, P. C., et al. (2013). Adipose-derived stem cells and keratinocytes in a chronic wound cell culture model: the role of hydroxyectoine. Int. Wound J. 12, 387-396. doi: 10.1111/iwj.12120

Wagner, W., and Wehrmann, M. (2007). Differential cytokine activity and morphology during wound healing in the neonatal and adult rat skin. J. Cell Mol. Med. 11, 1342-1351. doi: 10.1111/j.1582-4934.2007.00037.x

Xu, Y. Z., Wang, Q., Li, D. S., Wu, Z. H., Li, D. W., Lu, K. L., et al. (2016). Protective effect of Lithium chloride against hypoglycemia-induced apoptosis in beuronal PC21 cell. Neuroscience 330, 100-108. doi: 10.1016/j.neuroscience.2016.05.047

Xuan, Y., Chi, L., Tian, H., Cai, W., Sun, C., Wang, T., et al. (2016). The activation of the NF-kappaB-JNK pathway is independent of the PI3K-Rac1-JNK pathway involved in the bFGF-regulated human fibroblast cell migration. J. Dermatol. Sci. 82, 28-37. doi: 10.1016/j.jdermsci.2016.01.003

Xuan, Y. H., Huang, B. B., Tian, H. S., Chi, L. S., Duan, Y. M., Wang, X., et al. (2014). High-glucose inhibits human fibroblast cell migration in wound healing via repression of bFGF-regulating JNK phosphorylation. PLoS ONE 9:e108182. doi: 10.1371/journal.pone.0108182

Yie, J., Wang, W., Deng, L., Tam, L. T., Stevens, J., Chen, M. M., et al. (2012). Understanding the physical interactions in the FGF21/FGFR/beta-Klotho complex: structural requirements and implications in FGF21 signaling. Chem. Biol. Drug Design. 79, 398-410. doi: 10.1111/j.1747-0285.2012.01325.x

Zarse, K., Terao, T., Tian, J., Iwata, N., Ishii, N., and Ristow, M. (2011). Low-dose lithium uptake promotes longevity in humans and metazoans. Eur. J. Nutr. 50, 387-389. doi: 10.1007/s00394-011-0171-x

Zhang, H., Zhao, D., Wang, Z., and Zheng, D. (2010). Diazoxide preconditioning alleviates caspase-dependent and caspase-independent apoptosis induced by anoxia-reoxygenation of PC12 cells. J. Biochem. 148, 413-421. doi: 10.1093/jb/ mvq074

Zittermann, S. I., and Issekutz, A. C. (2006). Basic fibroblast growth factor (bFGF, FGF-2) potentiates leukocyte recruitment to inflammation by enhancing endothelial adhesion molecule expression. Am. J. Pathol. 168, 835-846. doi: 10.2353/ajpath.2006.050479

Conflict of Interest Statement: The authors declare that the research was conducted in the absence of any commercial or financial relationships that could be construed as a potential conflict of interest.

Copyright (c) 2017 Wang, Zhu, Sun, Wang, Shen, Cai, Sun, Chi, Wang, Song, Niu, Shen, Cong, Zhu, Xuan, Li and Jin. This is an open-access article distributed under the terms of the Creative Commons Attribution License (CC BY). The use, distribution or reproduction in other forums is permitted, provided the original author(s) or licensor are credited and that the original publication in this journal is cited, in accordance with accepted academic practice. No use, distribution or reproduction is permitted which does not comply with these terms. 